\title{
The Effects of Macroeconomic Instability and Inflation on Sustainable Real Growth in South African Firms
}

\section{Marolee Beaumont Smith}

School of Business Management, University of South Africa

\section{Charles N'Cho-Oguie}

Department of Economics, University of San Francisco

L W Murray and Daniel Blakley

Mclaren School of Business, University of San Francisco

\begin{abstract}
This empirical study is an investigation of the impact that inflation and other factors have had on the growth of business firms in South Africa. Using the model of sustainable growth, an empirical multivariate model is developed to test a variety of assumed relationships and to isolate the impact of inflation. A data set of South African firms' financial statements during the period 19831996 was assembled to permit a detailed examination of these firms' financial performance during South Africa's period of isolation. Utilising both direct and indirect measures of inflation, we determine that inflation affects growth in a negative manner. By combing firm-level and macro data issues relating to the endogeneity of inflation, we argue that macroeconomic instability is the true factor adversely affecting firm growth during this period of time.
\end{abstract}

JEL E31, L11, L25

\section{OVERVIEW}

In the last twenty years inflation in South Africa has fluctuated between an annual consumer price index high of 18,8 percent in 1986 to a low of 5,2 percent in 1999. In August 2002 inflation jumped to over 15 percent, the highest level in 13 years. Despite some controversy, it is generally accepted that inflation deters from a firm's growth potential. The primary objective of this research is to determine whether, using financial performance data of local firms, this has been true during South Africa's period of isolation. A secondary objective is to explore the impact of inflation on firm growth using alternative measures of inflation. In addition this research will investigate the extent to which firm 
management may be able to mitigate the damaging effects of inflation. Using sustainable growth modelling, various hypotheses are tested to identify the controllable and uncontrollable factors that collectively determine the extent to which firm performance is impaired by inflation.

\section{LITERATURE REVIEW}

The sustainable growth model produces an annual growth rate of real sales that can be maintained given certain financial policies and assumptions describing the firm's technological and competitive constraints. Higgins (1977; 1981; and 1984) put forth the original work on the sustainable growth problem. In the original Higgins framework, which did not address inflation, the firm's sustainable growth is determined by additions to retained earnings (via undistributed profits) and the resultant allowable increase in debt (via predetermined debt/equity ratio) to finance asset expansion and sales.

Early applications of this framework focus on the relationship between growth and changes in one or more of the constraining ratios rather than the realistic inclusion of inflation. Extensions of the model into the corporate planning literature by Murray, Doyle and Blakley (1988) Van Horne (1987) and Ellsworth (1985) for example, assume inflation will not impact growth unless the firm has a positive investment in net working capital. The reasoning here is that inflation will not reduce firm growth unless there is a requirement to finance inflation induced increases in current assets. ${ }^{1}$

Likewise, use of the sustainable growth framework to examine trade-offs between operating and financial parameters by Lewellen (1987), Seitz (1982), Fruhan (1986), Donaldson (1985), Clark, Clark and Verzilli (1985), Clark, Clark and Olson (1990) and Churchhill and Mullins (2001) simply assume a neutral impact of inflation. Inflation was not the primary focus of these studies and it was not included in model specification in either a robust or a realistic fashion.

A subsequent enhancement of the sustainable growth model by Doyle, Blakley and Murray (1994) more accurately captures the influence of inflation on capital intensity and profitability within the sustainable growth model. It is this formulation of sustainable growth that is briefly summarised below and will be used to empirically validate several hypotheses concerning firm growth ${ }^{2}$.

A more recent attempt by N'Cho-Oguie, Blakley, Murray and Beaumont Smith (2001) has been made to empirically validate similar hypotheses using data from multiple countries over different time periods. Obvious difficulties with 
this approach include different accounting standards as well as difficulties associated with temporal comparison of financial performance statistics.

The research presented below reflects firm performance data produced under the same accounting standards umbrella over the same time period. In addition, the data set used allows for alternative measures of inflation to be tested as to their impact on firm growth.

\section{THE SUSTAINABLE GROWTH MODEL}

The formal methodology used below is similar to that employed in the aforementioned sustainable growth literature. It is shown that by specifying given levels of financial leverage, capitalisation, profit retention, asset turnover, and other assumptions describing the firm's operating environment, it is possible to calculate the firm's resultant level of real sales growth. The structural equations capturing these relationships are specified and solved to find the firm's growth as a function of specific operating and financial variables.

Using sample data we first demonstrate the unequivocal effect of inflation; i.e., higher inflation is necessarily harmful to all positive-growth firms. We then investigate how different operating conditions and/or financial strategies affect inflation's impact. Thereafter we show under what conditions the harmful effects of inflation are more pronounced. Expressly, the more capital intensive the firm (i.e., the lower the sales to asset ratio), the greater the firm's investment in working capital as a percent of sales, the lower the firm's profit retention, and the lower the firm's debt to equity ratio, the more harmful is inflation to a firm's real rate of sales growth. Finally, we show that the incremental effects of higher inflation are not constant but vary significantly dependent on the existing level of inflation and various financial policies and operating conditions of the individual firm.

A unique aspect of this research is the development of a methodology designed to empirically validate these conclusions. Testable hypotheses are developed that can be investigated using financial data of firms operating primarily in economies where inflation varied considerably over a long period of time; e.g., South Africa.

\section{MODEL SPECIFICATION}

We begin developing the model of sustainable growth with the five stylised assumptions used in previous research ${ }^{3}$. 
1. Inflation is anticipated, constant and uniform with respect to factor input costs, product prices, current assets and current liabilities.

2. Book depreciation matches the actual straight-line deterioration of productive assets.

3. The capital structure and profit retention ratio are constant and no new equity is issued.

4. The profit margin on sales, net of depreciation and interest, is constant.

5. Real increases in sales are a constant proportion of the real increase in productive assets.

It is the intent of the methodology described below to control these standard assumptions in the initial empirical validation of the model and to isolate the impact of inflation on sustainable growth. The assumption of no multicollinearity between the parameters representing these assumptions is also consistent with previous research. For example, while profit retention adds to equity value and would, ceteris paribus, decrease the debt/equity ratio, we are implicitly assuming, as in previous studies of sustainable growth, that the debt/equity ratio is objectively held constant by the issuance of additional debt by the firm's management.

We now specify five equations, (1)-(5), which collectively capture the dynamic interaction of the firm's balance sheet and income statement consistent with the above assumptions:

$L_{t}=\lambda E_{t}$,

$P_{t}=\pi S_{t}-(1 / n) A_{t}-[1+\rho(1+i)] L_{t}$,

$E_{t}=E_{t-1}+\delta P_{t}$,

where $L_{t}$ represents the firm's liabilities, $E_{t}$ the firm's equity, and $\lambda$ the debt equity ratio. $P_{t}$ is the net equity cash flow at time $t$. $P_{t}$ is defined as the profit generated from sales $\left(\pi S_{t}\right)$ less: a) the necessary reinvestment in assets $\left((1 / n) A_{t}\right)$, and b) interest on debt $[1+\rho(1+i)] L_{t}$, where $\rho$ signifies the real interest rate (via the Fisher effect) and $i$ the rate of inflation.

Under the assumption that sales increases are a constant proportion, $\theta$, of real increases in assets ${ }^{4}$,

$$
\theta=\frac{S_{t}-(1+i) S_{t-1}}{(1-(1 / n))\left[A_{t}-(1+i) A_{t-1}\right]},
$$

that when solved for $S_{t}$ produces

$S_{t}=\theta(1-(1 / n))\left[A_{t}-(1+i) A_{t-1}\right]+(1+i) S_{t-1}$.

Lastly, assuming a constant proportional relationship, $\phi$, between net working capital and sales, the balance sheet constraint (equilibrium condition) can be specified as

$A_{t}=L_{t}+E_{t}-\phi S_{t}$, 
where $\phi S_{t}$ is the firm's net investment in working capital defined as current (non-productive assets necessary to support sales less spontaneous, non-interest bearing liabilities (i.e., accounts and wages payable).

Finally it is relatively straightforward to solve the 5 different equations for real sales growth $g$ as

$g=X /(1+i)-1$,

where

$X=-(1 / D)(\alpha \phi+1)$,

$\alpha=\theta(1-(1 / n))$, and

$D=\quad-\theta(1-1 / n)\{\phi+\lambda \delta \phi[i+\rho(1+i)]-(\lambda+1) \delta \pi\}-\{1+1 / n(\lambda+1) \delta+\lambda \delta$ $[i+\rho(1+i)]\}$.

Using equations (1)-(6) and sample input values we will now demonstrate how determinants of firm growth vary at different levels of inflation. ${ }^{6}$ Graphs (A)(D) in Figures 1 and 2 simulate how changes in the firm's debt equity ratio, profit retention, working capital requirements, and sales to asset ratio impact sustainable growth at varying levels of inflation.

In Figure 1 the results of simulating the effects of increasing inflation on firm growth at various levels of debt to equity, profit retention, working capital to sales, and sales to assets are presented. In all cases, as expected, higher levels of inflation has a negative impact on growth. It can also be observed that increases in sales to assets, debt to equity and profit retention ratios tend to increase growth while increases in working capital to sales reduce growth. 


\section{Figure 1 Sustainable growth}
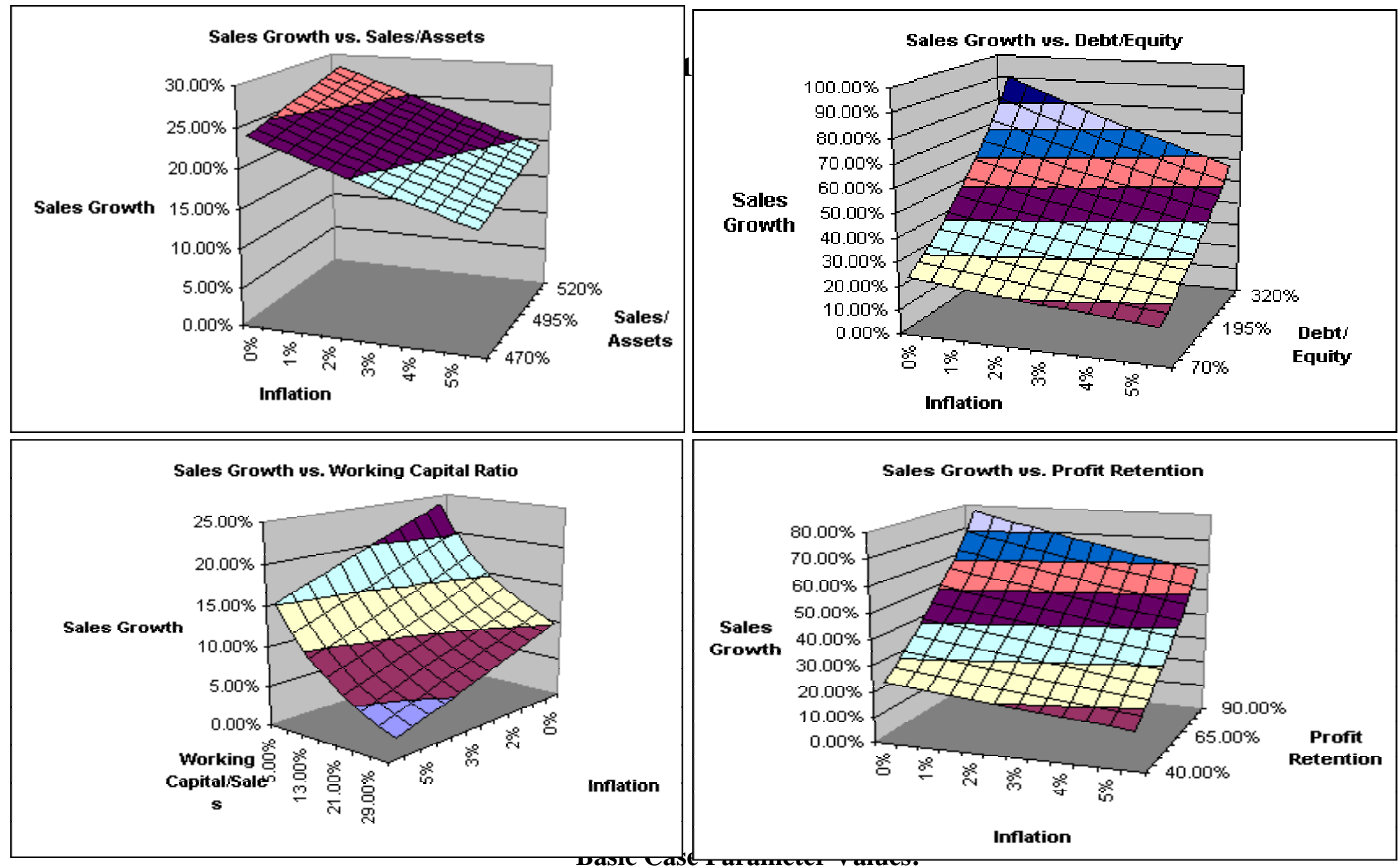

$\lambda$-debt/equity.$\pi$-profit margin $\mathrm{n}$ - asset life $\mathrm{i}$-inflation $\rho$-cost of capital

$\delta$ - profit retention $\theta$-sales/assets.$\varphi$-working 


\section{Figure 2 Sustainable growth elasticity}
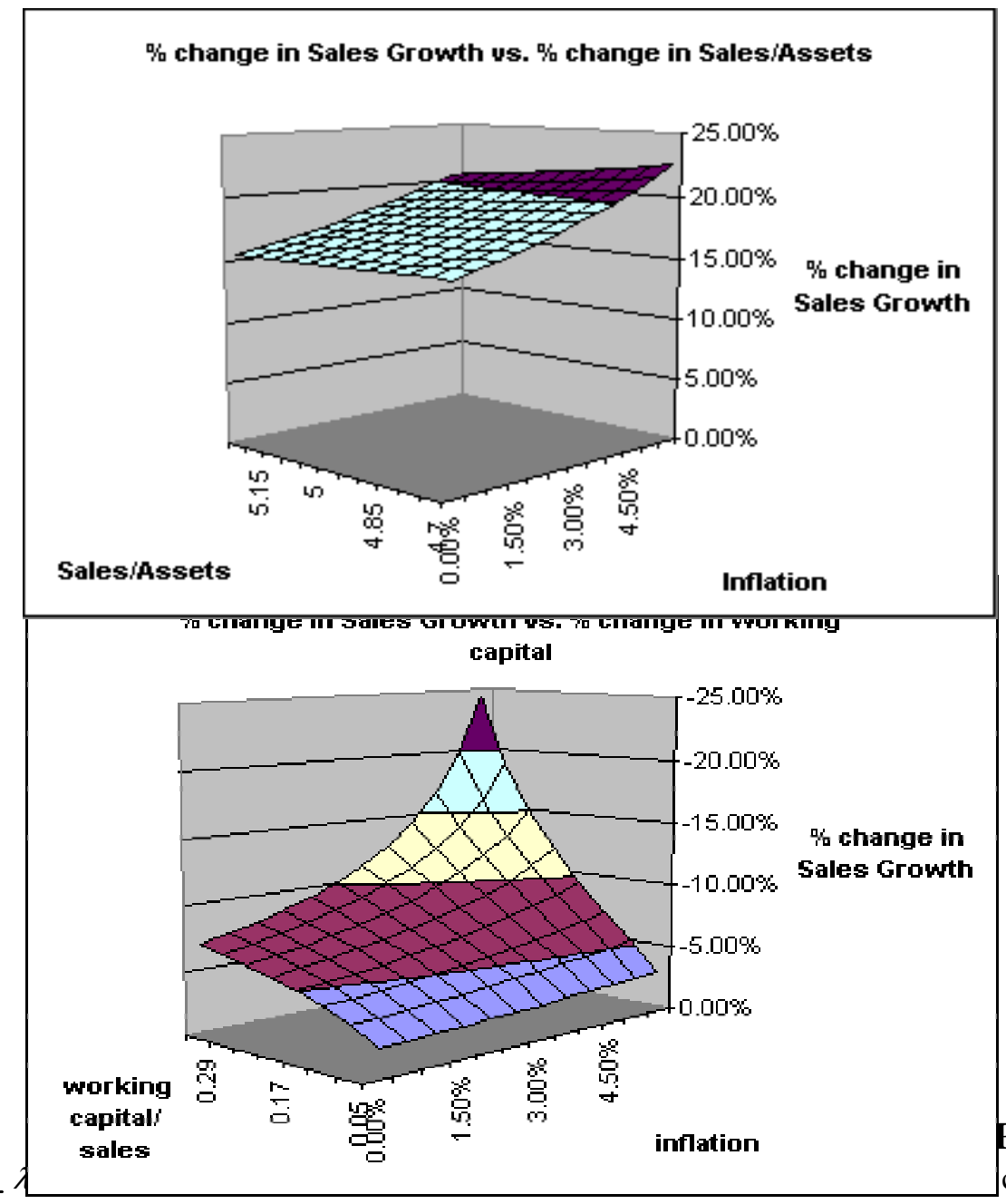

$\begin{array}{lllll}0.7 & 0.12 & 8 & 0 \%-5 \% & 0.05\end{array}$

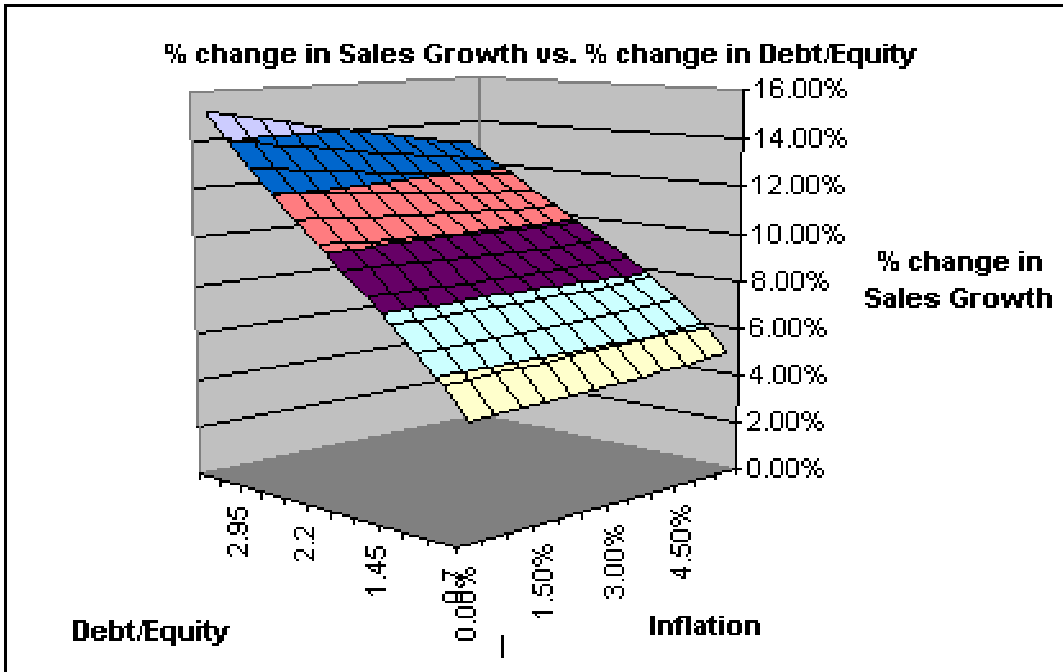

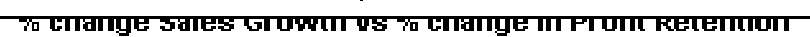

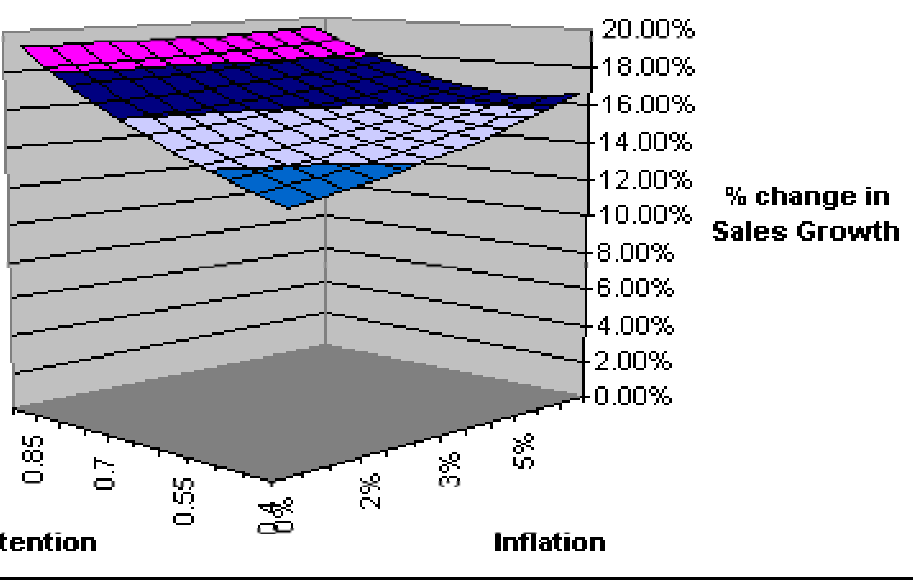

Profit Retention 


\section{EMPIRICAL VALIDATION}

\subsection{The data}

The main data set was acquired for the University of Pretoria's Bureau of Financial Analysis (BFA). The BFA database contains comprehensive financial information of firms listed on the Johannesburg Stock Exchange and produces standardised annual financial statements according to requirements of the South African Companies Act 1973. These include standardised balance sheets and income statements as well as other financial information. The data set consists of a panel of 135 firms with financial information recorded over 14 years (from 1983 to 1996). This covers the period of the 1980s when South Africa went through relative "financial isolation" because of international sanctions against the Apartheid government. Sanctions were rescinded in the aftermath of the release of Nelson Mandela in February 1992. In addition to the firm-level financial data, a number of macroeconomic data on South Africa were obtained from the 1999 World Bank World Development Indicators. This includes the real GDP growth rate, the CPI-inflation rate, the real exchange rate, the terms of trade, the domestic interest rate differential (i.e., domestic lending rate minus the deposit rate) and the external interest rate differential (i.e., the nominal lending rate minus LIBOR). Figure 3 describes trends in these key macroeconomic aggregates throughout the period 1983-96. 


\section{Figure 3 Macroeconomic performance data}
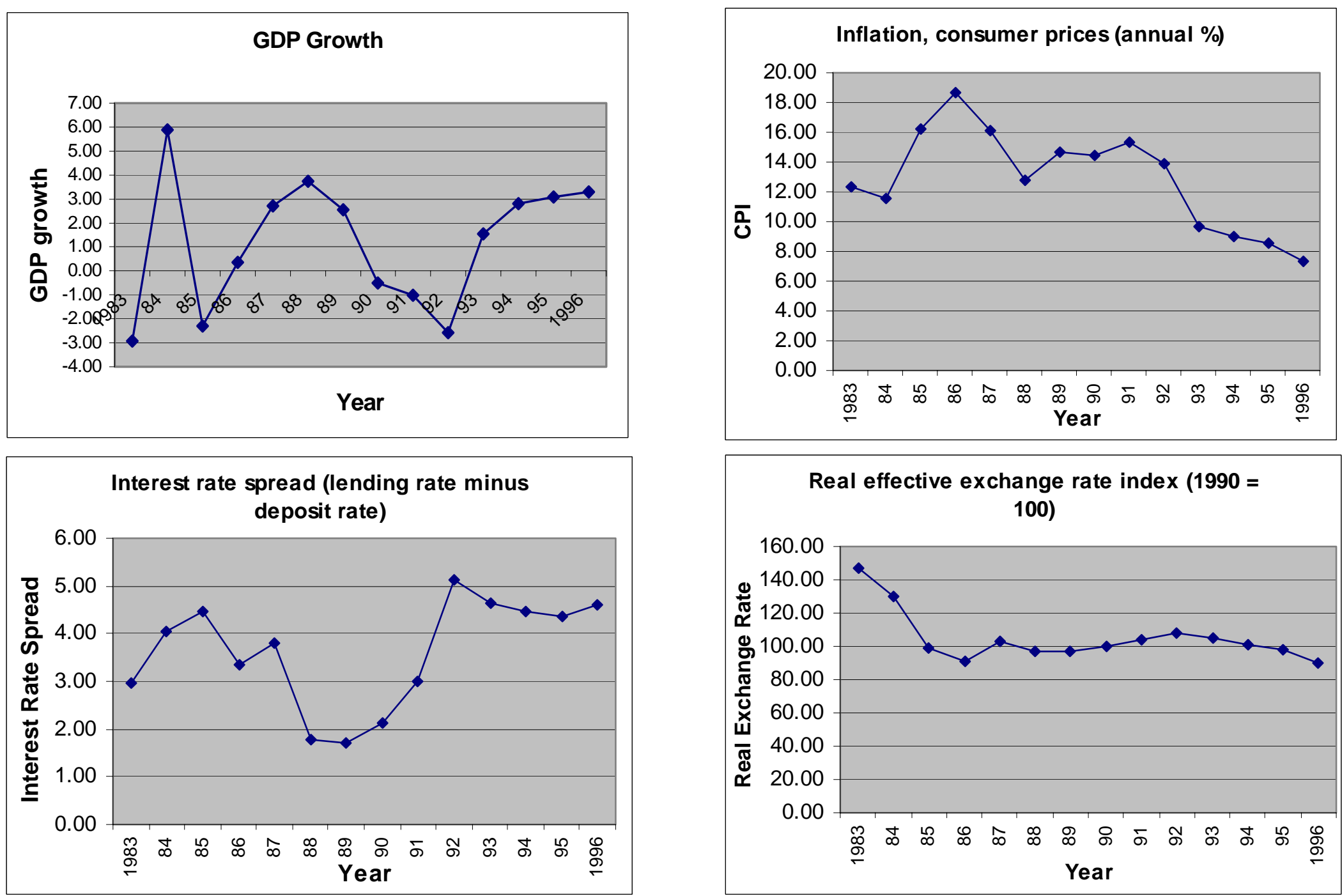


\subsection{Inflation, financial ratios and real growth}

The firm-level panel data combined with the macro-level financial data provide an ideal database for assessing the impact of inflation on financial ratios and growth, while controlling for overall macroeconomic conditions, including possible macro-level relations between inflation and aggregate growth. For the sustainable growth model estimation a pooled cross-section/times series analysis was used as it is most appropriate for exploiting the richness of panel data. The dependant variable is real sales growth (GR). The explanatory variables are the key financial ratios, namely: debt/equity (DER), profitability rate (PFR), Working capital/Sales (WKR) and Sales/Assets (SAR). Two hypotheses are derived:

$\mathrm{H}_{1} \quad$ With the exception of the working capital ratio, the other three ratios are positively related to real growth while working capital/sales has a negative impact on real growth.

$\mathrm{H}_{2} \quad$ The impact of financial ratios on growth is adversely affected by inflation where there is a positive link between financial ratio and growth (that is for DER, PFR and SAR); the converse is true where there is a negative link (WKR).

These hypotheses may be tested using the following pooled model specification: $G R_{f t}=c+\left(\lambda_{0}+\lambda_{1} * i\right) \cdot D E R_{f t}+\left(\pi_{0}+\pi_{1} * i\right) \cdot P F R_{f t}+\left(\phi_{0}+\phi_{1} * i\right) \cdot W K R_{f t}+$ $\left(\theta_{0}+\theta_{1} * i\right) \cdot S A R_{f t}+e_{f t}$

where $\mathrm{i}$ denotes the inflation rate measured by the consumer price index. Accordingly, the marginal effect of say the DER ratio on growth is $\left(\lambda_{0}+\lambda_{1} * i\right)$. Hypotheses $\mathrm{H}_{1}$ can be tested by checking that $\lambda_{0}>0$ and for $\mathrm{H}_{2}$ that the interaction coefficient $\lambda_{1}<0$. In other words, on impact, the debt/equity ratio positively affects real firm growth $\left(\lambda_{0}>0\right)$; but the marginal impact diminishes as inflation rises $\left(\lambda_{1}<0\right)$. We may proceed in a similar fashion for the PFR and the SAR ratios. Conversely, we would expect the working capital effect on growth to be negative $\left(\phi_{0}<0\right)$ and with a positive interaction with inflation $\left(\phi_{1}>0\right)$.

The model above is estimated using Generalised Least-Squared (GLS) techniques with cross-section weighting to control for possible heteroskedasticity. We estimated three alternative specifications of the above model, namely: (i) model with common intercept, c, for all firms; (ii) model with firm-specific intercepts $\left(\mathrm{c}_{\mathrm{ft}}\right)$ assumed to be fixed (fixed-effect model); (iii) model with firm-specific intercepts that are assumed random (random-effect model), under the assumption that firms in the sample constitute a random 
selection from a larger pool of firms. We then used the Haussman specification tests to select the most robust model ${ }^{7}$. Test results indicate that the fixed-effect model with cross-section weighting provides a superior fit relative to the other alternatives mentioned above. Therefore, in the following, we restrict our comments to the result of the fixed-effect specification. The results are summarised in Table 1.

Table 1 Inflation, financial ratios and firms growth: estimation results

\begin{tabular}{||l|c|c||}
\hline \multicolumn{1}{|c|}{ Variables } & Model 1 & Model 2 \\
\hline & Coefficient (t-ratios) & Coefficient(t-ratios $)$ \\
\hline Debt/equity $(\lambda)$ & $0.012822(1.73477)$ & $0.051669(2.255018)$ \\
\hline Profitability $(\pi)$ & $0.38714(5.666860)$ & $0.745551(2.761645)$ \\
\hline Working Capital/Sales $(\varphi)$ & $-0.005421(-2.230153)$ & $-0.287625(-3.059196)$ \\
\hline Sales/Assets $(\theta)$ & $0.024878(1.987801)$ & $0.016769(0.652430)$ \\
\hline Dividend payout $(\delta)$ & $-0.000330(-0.129839)$ & $-0.013017(-0.512799)$ \\
\hline Inflation $(\mathrm{i})$ & $-0.044636(-0.444402)$ & $2.682384(2.553607)$ \\
\hline Inflation Squared $\left(\mathrm{i}^{\wedge} 2\right)$ & $\mathrm{Ni}$ & $-9.890309(-2.690310)$ \\
\hline
\end{tabular}

Interactions, inflation and:

\begin{tabular}{|l|c|}
\hline Debt/equity & $-0.302537(-1.875988)$ \\
\hline Profitability & $-2.715674(-1.357695)$ \\
\hline Working capital/sales & $3.290037(3.007552)$ \\
\hline Sales/Assets & $-0.036738(-0.225837)$ \\
\hline Dividend payout & $0.071524(0.484845)$ \\
\hline
\end{tabular}

Note: /1. "ni" indicates that the particular variable is not included in the model. 12. All models have been estimated using GLS techniques on fixed-effect model specification with cross-section weighting. Each pool equation is weighted by an estimate of the cross-section residual standard deviation.

\section{- The Base model with no interaction terms}

Model 1 represents a straightforward econometric estimation of the sustainable growth model. Although, as argued later, this specification is rather "gross", the overall results seem to confirm our conjectures, namely that:

1 The effect, regardless of inflation, of higher debt to equity ratio $(\lambda)$, profitability $\operatorname{rate}(\pi)$, and sales to assets $(\theta)$ on firm growth are positive, while higher levels of working capital to sales $(\varphi)$ has a negative impact on firm growth. However, the impact of Dividend Payout rate (c) is insignificant.

2 Moreover, inflation is negatively associated with firm growth, although the contemporaneous impact appears insignificant. This suggests that further refining of the model may be needed for more conclusive results. 


\section{- The base model with interaction terms}

Model 2 disentangles two channels whereby inflation may affect real growth. One is the firm-level conduit, i.e. how firms' reaction to inflation may impact on financial ratios and hence, real growth. The other is the macro-level aggregate effect, which is the outcome of macro policies (fiscal and monetary) and aggregate demand and supply shocks, as covered in the mainstream macroeconomic literature ${ }^{8}$. The first channel is captured via the interaction terms in Model 2. As to the broad macro-level relations between inflation and aggregate growth, we resort to a flexible non-linear specification, whereby the marginal impact of inflation on real growth may vary at different inflation rates $^{9}$. A quadratic specification proves to yield the best results. The overall estimation results are summarised in column 3 of Table 1.

Overall, the results are consistent with those of our previous studies and are also far more robust than those of Model 1. In particular, the estimation results of Model 2 indicate that:

1 Adjusted for inflation, the respective marginal impacts of the Debt/equity ratio $\left(\lambda_{0}\right)$, the profitability rate $\left(\pi_{0}\right)$ and the sales to assets ratio $\left(\theta_{0}\right)$ are positive, whereas the working capital to sales ratio $\left(\varphi_{0}\right)$ is negative. Most coefficients are statistically significant, with the exception of the sales to assets ratio $(\theta 0)$ which appears weaker, although still positive. The dividend pay out ratio remains insignificant as in the previous model.

2 Moreover, the interaction terms in model 2 are negative for the debt/equity ratio $\left(\lambda_{1}\right)$, the profitability rate $\left(\pi_{1}\right)$ and the sales/assets ratio $\left(\theta_{1}\right)$, but positive for the working capital to sales ratio $\left(\varphi_{1}\right)$. This supports our conjecture that higher inflation tends to dampen the growth-effect of higher debt/equity ratio, profitability rate and sales to assets ratio, while lessening the growth-inhibiting impact of higher working capital to sales ratio. In other words, at low inflation rate, firms may significantly gain from raising the "growth-enhancing" ratios and lowering the "growthinhibiting" ones. However, such marginal gains vanish at higher inflation levels.

\subsection{Macroeconomic instability, cost of capital, financial ratios and real growth}

As expected, when adjusted for inflation, the relationship between the debt/equity ratio, the firm's profitability and sales-to-assets are positively related to firm growth. Although consistent with the findings of previous studies, the model is plagued with a number of key econometric and empirical modelling issues. At the heart of the matter is the well-known problem of endogeneity of inflation in the growth accounting model, or simultaneity between inflation and growth. In other words, inflation itself may be endogenous to the growth 
process, caused by growth, affecting growth in a reverse manner, and/or simultaneously determined with growth as reflecting macroeconomic conditions, policy choices as well as exogenous shocks. This would raise difficulties both in the econometric estimation process as well as in the interpretation of model result.

From the outset, it is important to note that the endogeneity of inflation is much less of an issue in the firm-level approach than in the macro-level approach in the sustainable growth model. For as long as each firm remains small relative to the entire market, aggregate growth as well as inflation may be regarded as "exogenous" to the firm, although in the final analysis, aggregate growth is the macro outcome of firm behaviour and firm growth. In other words, the econometric model would still hold in the case of firm-level data, even assuming that inflation and aggregate growth are interrelated in an "endogenous" fashion.

Unfortunately, even for firm-level data as in this study, "endogeneity" still raises a number of econometric issues relative to model specification. This is further complicated by the dynamics - short-term versus long-term - of the relationship between inflation and aggregate growth, which makes it difficult to unambiguously predict the sign of the inflation coefficient in the sustainable growth model. First, consider the most frequent case when arguably, inflation and growth may both be intertwined in a two-way relationship, namely a case of "reverse causality". For example, according to the orthodox Keynesian AD/AS model, growth in excess of capacity may "cause" inflation - at least in the short run, although, in a boomerang effect, the higher inflation may in fine dampen growth. This scenario is likely in the case of expansionary fiscal and monetary policies, or in the case of positive terms-of-trade shock and non-sterilised foreign exchange inflows as in the Dutch disease syndrome. It is worth noting that in those cases, inflation and growth tend to be positively related in the short run but negatively thereafter, so that a "carelessly" specified regression model may yield ambiguous results, unsettled signs and leads one to misconstrue effect for cause. In this case, our previous econometric model would tend to provide biased estimates of the impact of inflation on growth, and the difference between short run and long run dynamics may result in ambiguous sign and unstable coefficients.

Another common case of "endogeneity" may arise from "joint-causality", that is when both inflation and real growth are simultaneously determined by the same "event", typically a macroeconomic shock. For example, an adverse supply shock (weather, import cost, etc.) may simultaneously dampen real growth while at the same time raising cost and prices. In this case, inflation and real growth would tend to be negatively related, although such a relationship may be 
"altered" by stabilisation policies and, in any case, does not imply any direct causality.

Kocherlakota (1996) and Barro (1997) pointed out yet another possible source of "endogeneity" of inflation, namely when monetary policy is set on a given path by an independent monetary authority (i.e. a targeted growth rate of money supply) and does not necessarily accommodate output fluctuations. In this case, an adverse shock that contracts real output will de facto result in excess money supply, hence inflation, implying a negative association between inflation and real growth. Kocherlakota suggested a methodology for coping with this last cause of endogeniety of inflation, and Barro resorted to lagged-inflation as an instrument for estimating the growth impact of inflation while controlling for possible reverse or joint causality.

Our view is that with model based upon firm-level data, the endogeneity problem as such is lessened. But from the preceding discussions, a much larger problem transpires, namely the issue of efficient model specification. Ultimately, inflation and growth are both the outcomes of policy choices, exogenous shocks and policy responses to those shocks. The core issue is macroeconomic instability which is unambiguously detrimental to real growth. The extent to which such instability may translate into inflation, nominal exchange rate and/or interest rate fluctuations would depend upon the conditions of a particular country, including foreign exchange regime, trade policy, institutional preferences, etc. For example, in the context of a country with a pegged exchange rate system (fixed, or currency board), where inflation must be aligned on that of the anchor country, macroeconomic instability may not be fully absorbed through price fluctuations, but by real interest rate fluctuations, such as in Argentina and in most of the CFA countries of West Africa. Likewise, a country facing frequent terms-of-trade shocks may choose to target real exchange rate stability, as opposed to nominal price stability as a more efficient means for macroeconomic stabilisation. Finally, a country facing financial instabilities may choose a combination of nominal exchange depreciation, real interest rate hike and capital control as means for fighting capital flight and reducing macroeconomic instability. We argue that this may have been the case for South Africa during its period of isolation and sanctions.

Consequently, we decide to recast the model in order to assess the real cost of macroeconomic instability. To this end, we distinguish two classes of macro instabilities depending on which market - real or financial - is primarily affected. In one case, shocks and policies would typically impact the real sector in the short run. This is the case for expansionary fiscal policy, terms-of-trade shocks and adverse supply shocks. Typically, these policies or shocks would adversely impact growth via real exchange rate appreciation, or more generally, 
through real exchange rate misalignment ${ }^{10}$. Therefore, we choose to use the real exchange rate, rather than the CPI-inflation, as a proxy for "real macroeconomic instability". Our key point is that what matters most is not so much the level of inflation, but rather the resulting degree of real exchange rate misalignment in the face of macroeconomic disturbances. Arguably, the adverse growth- impact of such shocks may be mitigated by appropriate policies that would prevent real exchange rate misalignment ${ }^{11}$. This appears to have been the case for South Africa where a delicate mix of fiscal and monetary policy during the 1980s and the 1990s has tried to accommodate several objectives, namely domestic price stability, foreign exchange stability and real growth in the face of terms-of-trade shocks and relative financial isolation.

Secondly, we consider "financial instability", that is macroeconomic instability that is primarily bred in financial market disturbances, such as in the 1994 Mexican pesos crisis, the 1997-98 Asian crisis, or in the case of "financial isolation" as faced by South Africa because of sanctions against the Apartheid government ${ }^{12}$. Such instability typically leads to high real interest rate, raising the cost of capital to domestic firms, and thus dampening real growth. It is worth noting that in such an environment, nominal price-inflation may still remain "in check" as a matter of policy choice (such as in the case of Argentina, the CFA Franc zone before in the eve of the 1994 devaluation, etc.) ${ }^{13}$, while real interest rate would typically rise way beyond "fisher parity" level. We therefore choose to accommodate this class of disturbances by including the gap between the domestic interest rate and the international interest rate into the growth equation.

We therefore augmented the previous model by including the real exchange rate (RER), the interest rate gap (INTGAP) among the explanatory factors. Following standard IMF practices, we compute the real exchange rate as the effective trade-weighted nominal exchange rate multiplied by the ratio of the domestic CPI-inflation rate to the average (trade-weighted) CPI-inflation rates of South-Africa's partners. As to the interest rate gap, we use the interest rate differential between the domestic lending rate and the dollar LIBOR rate. We also computed an alternative measure of the real cost of capital (rho), using the Jorgenson-Hall "rental cost" approach ${ }^{14}$. Means statistics on these data are provided in Table 2 . We still provide for a residual effect of macro instability by including the CPI-measure of inflation in the model. 
Table 2 Inflation, financial ratios and firms growth: Estimation results

\begin{tabular}{||l|l|c||}
\hline \multicolumn{1}{|c|}{ Variables } & \multicolumn{1}{c|}{ Model 3 } & Model 4 \\
\hline & \multicolumn{1}{|c|}{ Coefficient (t-ratios) } & $\underline{\text { Coefficient(t-ratios ) }}$ \\
\hline Debt/equity (Lambda) & $0.041308(1.847702)$ & $0.041949(1.811451)$ \\
\hline Profitability (Pi) & $0.622873(2.239409)$ & $0.639467(2.286807$ \\
\hline Working Capital/Assets (Phi) & $-0.299226(-3.256679)$ & $-0.282274(-2.966310)$ \\
\hline Sales/Assets (theta) & $0.062540(2.255592)$ & $0.040833(1.507374)$ \\
\hline Dividend payout (delta) & $-0.020235(-0.780989)$ & $-0.016979(-0.653529)$ \\
\hline Inflation (i) & $5.774646(4.724071)$ & $4.395913(3.324573)$ \\
\hline Inflation Squared (i`2) & $-23.76622(-5.441769)$ & $-19.02117(-3.73614)$ \\
\hline Real Exchange Rate (RER) & $-0.208732(-4.727125)$ & $-0.165273(-3.300424)$ \\
\hline $\begin{array}{l}\text { Interest Rate Differential } \\
\text { (INTGAP) }\end{array}$ & $-1.409267(-9.984925)$ & $\mathrm{ni}$ \\
\hline Real Cost of Capital (rho) & \multicolumn{1}{|c|}{$\mathrm{ni}$} & $-0.520020(-3.252987)$ \\
\hline
\end{tabular}

Interactions, inflation and:

\begin{tabular}{||l|c|c||}
\hline \hline Debt/equity & $-0.214018(-1.368087)$ & $-0.220774(-1.363237)$ \\
\hline Profitability & $-2.612686(-1.284219)$ & $-1.942677(-0.937895)$ \\
\hline Working capital/assets & $3.430705(3.209554)$ & $3.231432(2.918550)$ \\
\hline Sales/Assets & $-0.028036(-0.160596$ & $-0.039860(-0.233888)$ \\
\hline Dividend payout & $0.104912(0.690224)$ & $0.091221(0.607252)$ \\
\hline
\end{tabular}

Note: "ni" indicates that the particular variable is not included in the model

The estimation results are shown in Models 3 and 4. The previous results (the relations between financial ratios and firm growth) still hold, with even higher degree of statistical significance. Moreover, the results show that all measures of macroeconomic instability (RER, INTGAP or RHO) are all significantly growth-inhibiting. But with the augmented model, the interactions between CPIinflation and financial ratios have become less significant, although still with the conjectured signs. Overall, Model 3 and 4 provides the most convincing fit to the sustainable growth model.

\section{CONCLUSION}

To summarise the findings, the empirical econometric model suggests that: (1) inflation does negatively affect mean growth rate; (2) the debt to equity, sales to assets and profitability ratios are all positively associated with growth, and adversely affected by high inflation; (3) as expected, the working capital to sales ratio is negatively related to growth and positively affected at the margin by high inflation, although not all statistics are significant.

Moreover, our approach, combining firm-level data with macro data provided valuable insights in the complex relationship between inflation and growth, as 
studied in the sustainable growth literature and the increasing body of purely macroeconomic work on the subject. For instance, the sustainable growth literature has mostly concentrated attention on inflation and how it may impact real growth, and our previous studies have contributed to strengthening the case for a adverse effect. This empirical work constitutes an improvement with respect to previous work, by dwelling on the centrality of macroeconomic instability as the true factor adversely affecting growth, and allowing for various measures of instability.

The instruments we used are more complete in that they capture the outcome of shocks as well as stabilisation policy choices (nominal price, nominal exchange rate, interest rate, etc.) In so doing, we argue that the core issue of growth sustainability is macroeconomic instability, of which traditional CPI-inflation may only be an incomplete indicator. From the macro standpoint also, our approach combining firm-level and macro data is most efficient for handling issues related to the endogeneity of inflation and other issues related to model specification, such as disentangling short-term and long-term dynamics.

However, the empirical analysis still has a number of essentially data-related limitations necessitating further investigation. For example, in a model that involves anticipation, the trend in inflation rate (acceleration vs. deceleration) may prove more pertinent than the actual rate of inflation in explaining firms' growth rate, financial strategy, and the concomitant financial ratios. By the same token, as we focus attention on macroeconomic instability, it may prove even more pertinent to distinguish the "trend effect" (mean trend of inflation) from the "variability effect" (variance in the rate of inflation) on real growth. Depending on the extent of anticipations, the "variability effect" may prove even more important than the "trend effect".

Unfortunately, disentangling those effects would need much longer time-series and a cross-country approach. This is because of the stylised fact that the two effects tend to be contemporaneous, that is where mean inflation is high, the higher the variability of inflation ${ }^{15}$. To assess all these, a much longer timeseries and a larger pool of countries is needed. Within this, it may also be possible to differentiate the impact of inflation on growth depending on the level of financial development as indicated by various financial depth ratios.

Another alternative gaining popularity is a macro-level cross-country analysis of the determinants of growth, where inflation would be a key explanatory variable among others, as has been done in Barro's (1997) cross-country studies. Such an analysis could be extended to include country-level macro/financial variables which would "proxy" the firm-level financial ratios used in the sustainable growth model. 
Our investigations will progress in all three dimensions, namely (i) the single country multiple-firm approach (a cross-section of firms operating in the same country environment as in this study), the cross-country macro analysis of the determinants of growth and (iii) the cross-country/cross-firm approach (a crosssection of countries and firms over a time period, as in our previous study on Mexico and New Zealand combined). We believe that each of the three "data structures" and approaches has some unique features, which will provide valuable insight into the complex relation between growth and inflation. Finally, the impact of macro instability may also depend on a number of firm characteristics, such as tradability, firm size, etc. This could be the subject of future studies.

Meanwhile, none of the above limitations is so severe as to taint the conclusions derived from the study. In light of the various models and test procedures used, it appears that the results of the empirical investigations are robust enough to provide an empirical validation of the conjectures of the theoretical model. By all indications, high inflation appears detrimental to sustainable firm growth.

\section{ENDNOTES}

1 A notable exception is the Johnson (1981) model formulation that shows plausible conditions under which inflation will increase firm growth.

2 Appendix B is a replication of the proof from Doyle, et al. (1994) showing inflation necessarily reduces sustainable growth for all positive growth firms, regardless of working capital investment.

3 The model developed by Doyle, et al. (1994) modified assumption (5) by linking real sales to real assets, rather than real sales to nominal assets as assumed in earlier research. See Higgins $(1977,1981,1984)$ and Johnson (1981).

4 We assume assets acquired in the current period are depreciated on a straight line basis.

5 The mathematical derivation of $\mathrm{g}$ is found in Appendix A.

6 The base input values used to generate the simulated output were as follows: $\lambda=1, \pi=.05, n=10, i=0, \rho=.03, \delta=.75, \theta=5$ and $\varphi=.1$

7 A good summary review of the GLS technique and the Haussman specification test is provided in Greene, 2000, Chapter 7.

8 Briault (1995) provides a good review of the abundant literature on the theoretical and empirical work on the cost of inflation.

9 Even though it is generally accepted that high inflation is detrimental to growth, there is no clear consensus in the macroeconomic literature with respect to the linearity of the relationship. In his comprehensive work on the determinants of growth, Barro, 1997, established that the negative 
impact of inflation on growth appears especially significant when inflation rate is in the middle range (between 15 percent and 40 percent) or the upper range (over 40 percent). But the evidence is not overwhelming as to the significance of a negative effect of inflation on grow for low levels and low variability inflation rates. Hence our prudent approach of a non-linear specification that would allow for variable marginal impacts, depending on the inflation range.

10 For a comprehensive analysis of how real exchange rate misalignment dampens real growth, see Hinkle and Montiel (eds), World Bank, 2000.

11 For more on this, see the comprehensive work of Hinkle and Monteil, 1999.

12 In such a case, monetary authorities would typically pursue a "mixed" policy, using as much as possible a combination of foreign exchange interventions, reserve and high real interest rate policy to support the currency and to fight capital flight. In the end, inflation may be in check, as well as nominal exchange rate; but the real interest rate would rise significantly, which would adversely impact real growth.

13 This is also the case for the pegged system of China, or the currency-board system of Hong Kong and Malaysia.

14 Accordingly, the rental cost of capital (rho) per unit price of capital good is the real interest rate (nominal adjusted for expected inflation) net of depreciation. We have assumed a depreciation rate of 10 per cent.

15 For example, Barro (1997) has shown a positive association between the mean rate of inflation and the variance standard deviation of inflation, for a cross-section of 117 countries over the 1960-1990 period.

The authors acknowledge the helpful contributions of research assistants, Patrick Storey, Dapo Babajide, and Kristina Miles and particularly the technical assistance of Stanley Nel, Dean and Professor of Mathematics, University of San Francisco, with the Appendices. We also wish to acknowledge the helpful technical assistance from Florence Charlier, especially in the econometric analysis. 


\section{APPENDIX A}

It is relatively straightforward to reduce the five equations to a two-dimensional linear system of homogenous, constant coefficient, first order difference equations. From (1) and (5) we obtain

$A_{t}=(\lambda+1) E_{t}-\phi S_{t}$

and hence

$A_{t}-A_{t-1}=(\lambda+1) E_{t}-E_{t-1}-\phi\left(S_{t}-S_{t-1}\right)$.

Thus, using (3) and simplifying, we find that

$A_{t}-A_{t-1}=(\lambda+1) \delta\left\{\pi S_{t}-\frac{1}{n} A_{t}-[i+\rho(1+i)] L_{t}\right\}-\phi\left(S_{t}-S_{t-1}\right)$.

However, by (1) and (A.1), $L_{t}=\left(\lambda\left(A_{t}+\phi S_{t}\right)\right) /(\lambda+1)$. Substituting into (A.3) we therefore obtain

$A_{t}-A_{t-1}=\{(\lambda+1) \delta \pi-\lambda \delta c[i+\rho(1+i)]-\phi\} S_{t}$

$-\left\{\frac{1}{n}(\lambda+1) \delta+\lambda \delta[i+\rho(1+i)]\right\} A_{t}+\phi S_{t-1}$.

Collecting terms and rearranging now yields

$\{\phi+\lambda \delta \phi[i+\rho(1+i)]-(\lambda+1) \delta \pi\} S_{t}+\left\{1+\frac{1}{n}(\lambda+1) \delta+\lambda \delta[i+\rho(1+i)]\right\} A_{t}=\phi S_{t-1}+A_{t-1}$

A.4

Finally (4) can be rewritten as

$S_{t}-\theta(1+(1 / n)) A_{t}=(1+i) S_{t-1}-\theta(1-(1 / n))(1+i) A_{t-1}$.

In order to solve the system defined by (A.4) and (A.5), it is convenient to express these equations in matrix form. We define

$\Psi=\left(\begin{array}{cc}\phi+\lambda \delta \phi[i+\rho(1+i)]-(\lambda+1) \delta \pi & 1+\frac{1}{n}(\lambda+1) \delta+\lambda \delta[i+\rho(1+i)] \\ 1 & -\theta\left(1-\frac{1}{n}\right)\end{array}\right)$

and $\Phi=\left(\begin{array}{cc}\phi & 1 \\ 1+i & -\theta\left(1-\frac{1}{n}\right)(1+i)\end{array}\right)$.

Then (A.4) and (A.5) can be rewritten as the first order system $\psi\left(\begin{array}{c}S_{t} \\ A_{t}\end{array}\right)=\phi\left(\begin{array}{c}S_{t-1} \\ A_{t-1}\end{array}\right)$

from which it follows immediately that

$\left(\begin{array}{c}S_{t} \\ A_{t}\end{array}\right)=\psi^{-1} \phi\left(\begin{array}{c}S_{t-1} \\ A_{t-1}\end{array}\right)$.

Thus, we can represent (1) - (5) using matrix notation using (A.6) and (A.7) as $\left(\begin{array}{c}S_{t} \\ A_{t}\end{array}\right)=M\left(\begin{array}{c}S_{t-1} \\ A_{t-1}\end{array}\right)$

A. 8

where $\mathrm{M}$ is a $2 \times 2$ matrix defined as follows: Let

$D=-\theta\left(1-\frac{1}{n}\right)\{\phi+\lambda \delta \phi[i+\rho(1+i)]-(\lambda+1) \delta \pi\}-\left\{1+\frac{1}{n}(\lambda+1) \delta+\lambda \delta[i+\rho(1+i)]\right\}$, 


$$
\begin{aligned}
& a=\frac{1}{D}\left[-\theta\left(1-\frac{1}{n}\right)+(1+i)\left\{1+\frac{1}{n}(\lambda+1) \delta+\lambda \delta[i+\rho(1+i)]\right\}\right] \\
& b=-\frac{1}{D} \theta\left(1-\frac{1}{n}\right)\left[1+(1+i)\left\{1+\frac{1}{n}(\lambda+1) \delta+\lambda \delta[i+\rho(1+i)]\right\},\right. \\
& c=\frac{1}{D}[-\theta+(1+i)\{\phi+\lambda \delta \phi[i+\rho(1+i)]-(1+\lambda) \delta \pi\}], \\
& d=\frac{1}{D}\left[1+\theta\left(1-\frac{1}{n}\right)(1+i)\{\phi+\lambda \delta \phi[i+\rho(1+i)] \delta(1+\lambda) \delta \pi\}\right]
\end{aligned}
$$

and set $M=\left(\begin{array}{ll}a & b \\ c & d\end{array}\right)$.

Once $A_{t}$ and $S_{t}$ have been found by solving (A.8), $L_{t}$ and $E_{t}$ are determined by (1) and (5), and then $P_{t}$ is given by (3).

From standard difference equation theory it follows that the general solution of (13) can be expressed in terms of the eigenvalues and eigenvectors of the coefficient matrix $M$. Specifically suppose the eigenvalues of $M$ are $X_{1}$ and $X_{2}$ with corresponding eigenvectors and. Then the general solution of (A.8) is $\left(\begin{array}{l}S_{t} \\ A_{t}\end{array}\right)=V_{1}\left(\begin{array}{l}\lambda_{11} \\ \lambda_{21}\end{array}\right) X_{1}^{t}+V_{2}\left(\begin{array}{c}\lambda_{12} \\ \lambda_{22}\end{array}\right) X_{2}^{t}$

where $V_{1}$ and $V_{2}$ are arbitrary constants. These constants will be determined by the initial values of $S$ and $A$. By (A.15), the eigenvalues of $M$ are the roots of the quadratic equation

$\operatorname{det}\left(\begin{array}{cc}a-x_{i} & b \\ c & d-x_{i}\end{array}\right)=0$.

A. 16

Using (A.9) - (A.13), this quadratic is readily solved to yield

$$
X_{1}=-(1 / D)(\alpha \phi+1) \text {, }
$$

$X_{2}=X_{1}-(\beta / \alpha)-\alpha \mathrm{c}$,

Where $\alpha=\theta(1+(1 / n))$. 


\section{APPENDIX B}

Theorem. If $V^{*}>0$, then $(\partial \mathrm{V} * / \partial i)<0$.

Proof. From (A.17), (A.19), (25) it follows that $V^{*}=-\frac{1}{D(1+i)}(\alpha \phi+1)-1$.

Hence

$$
\frac{\partial V^{*}}{\partial i}=\frac{(\alpha \phi+1)}{[D(1+i)]^{2}} \frac{\partial}{\partial i}(1+i) D
$$

since both $\alpha$ and $\phi$ are independent of $i$. By (A.9) and (A.19),

$D=-(1+\alpha \phi)\{1+\lambda \delta[i+\rho(1+i)]\}+(1+\lambda) \delta(\alpha \pi-(1 / n))$,

so that $(\partial D / \partial i)=-(1+\alpha \phi) \lambda \delta(1+\rho)$.

Thus $\frac{\partial}{\partial}[(1+i) D]=-(1+\alpha \phi)(1+\rho)(1+i) \delta \lambda+d$.

By assumption, $n \geq 1$ and $\theta>0$, and thus $\alpha \geq 0$. Since $\rho, i, \delta$, and $\lambda$ are all non-negative, it therefore follows that

$-(1+\alpha \phi)(1+\rho)(1+i) \leq 0$.

Suppose now that $g \geq 0$. Then by (B.1),

$1 / D \leq-(1+i) /(1+\alpha \phi)<0$.

Hence $D<0$, and now (B.5) and (B.6) give

$\frac{\partial}{\partial i}[(1+i) D]<0$.

B. 8

Since $1+\alpha \phi>0$, it follows immediately from (B.2) and (B.8) that $\left(\partial V^{*} / \partial i\right)<0$. 


\section{APPENDIX C}

\section{ESTIMATED MODELS OF GROWTH, INFLATION AND FINANCIAL RATIOS}

\section{Model 1 Base model relating growth to inflation and financial ratios}

Date: 07/29/01 Time: 08:33

Sample: 19841995

Included observations: 12

Number of cross-sections used: 134

Total panel (unbalanced) observations: 1415

Cross sections without valid observations dropped

\begin{tabular}{|l|c|c|c|c|}
\hline \multicolumn{1}{|c|}{ Variable } & Coefficient & Std. Error & t-Statistic & Prob. \\
\hline LA? & 0.012822 & 0.007391 & 1.734778 & 0.0830 \\
\hline PI? & 0.387147 & 0.068318 & 5.666860 & 0.0000 \\
\hline PH? & -0.005421 & 0.002431 & -2.230153 & 0.0259 \\
\hline TH? & 0.024878 & 0.012515 & 1.987801 & 0.0470 \\
\hline DE? & -0.000330 & 0.002544 & -0.129839 & 0.8967 \\
\hline GRPCPI & -0.044636 & 0.100440 & -0.444402 & 0.6568 \\
\hline
\end{tabular}

Prob(F-statistic) $\quad 0.000000$

Model 2 Augmented model: Growth, financial ratios and Inflation, with interactions terms

Dependent Variable: GR?

Method: GLS (Cross Section Weights)

Date: 07/29/01 Time: 08:42

Sample: 19841995

Included observations: 12

Number of cross-sections used: 134

Total panel (unbalanced) observations: 1415

Cross sections without valid observations dropped

\begin{tabular}{|l|c|c|c|c|}
\hline \multicolumn{1}{|c|}{ Variable } & Coefficient & Std. Error & t-Statistic & Prob. \\
\hline LA? & 0.051669 & 0.022913 & 2.255018 & 0.0243 \\
\hline PI? & 0.745551 & 0.269966 & 2.761645 & 0.0058 \\
\hline PH? & -0.287625 & 0.094020 & -3.059196 & 0.0023 \\
\hline TH? & 0.016769 & 0.025703 & 0.652430 & 0.5142 \\
\hline DE? & -0.013017 & 0.025385 & -0.512799 & 0.6082 \\
\hline GRPCPI*LA? & -0.302537 & 0.161268 & -1.875988 & 0.0609 \\
\hline GRPCPI*PI? & -2.715674 & 2.000209 & -1.357695 & 0.1748 \\
\hline
\end{tabular}


Model 2 continued

\begin{tabular}{||l|c|c|c|c||}
\hline \multicolumn{1}{|c|}{ Variable } & Coefficient & Std. Error & t-Statistic & Prob. \\
\hline GRPCPI*PH? & 3.290037 & 1.093925 & 3.007552 & 0.0027 \\
\hline GRPCPI*TH? & -0.036738 & 0.162676 & -0.225837 & 0.8214 \\
\hline GRPCPI*DE? & 0.071524 & 0.147520 & 0.484845 & 0.6279 \\
\hline GRPCPI & 2.682384 & 1.050430 & 2.553607 & 0.0108 \\
\hline GRPCPI^2 & -9.890309 & 3.676271 & -2.690310 & 0.0072 \\
\hline Prob(F-statistic) & 0.000000
\end{tabular}

Model 3 Full model: Growth, financial ratios and the cost of macroeconomic instability

Dependent Variable: GR?

Method: GLS (cross section weights)

Date: 07/29/01 Time: 08:56

Sample: 19841995

Included observations: 12

Number of cross-sections used: 134

Total panel (unbalanced) observations: 1415

Cross sections without valid observations dropped

\begin{tabular}{|l|c|c|c|c||}
\hline \multicolumn{1}{|c|}{ Variable } & Coefficient & Std. Error & t-Statistic & Prob. \\
\hline LA? & 0.041308 & 0.022356 & 1.847702 & 0.0649 \\
\hline PI? & 0.622873 & 0.278142 & 2.239409 & 0.0253 \\
\hline PH? & -0.299226 & 0.091881 & -3.256679 & 0.0012 \\
\hline TH? & 0.062540 & 0.027727 & 2.255592 & 0.0243 \\
\hline DE? & -0.020235 & 0.025909 & -0.780989 & 0.4350 \\
\hline GRPCPI*LA? & -0.214018 & 0.156436 & -1.368087 & 0.1715 \\
\hline GRPCPI*PI? & -2.612686 & 2.034455 & -1.284219 & 0.1993 \\
\hline GRPCPI*PH? & 3.430705 & 1.068904 & 3.209554 & 0.0014 \\
\hline GRPCPI*TH? & -0.028036 & 0.174575 & -0.160596 & 0.8724 \\
\hline GRPCPI*DE? & 0.104912 & 0.151998 & 0.690224 & 0.4902 \\
\hline GRRER & -0.208732 & 0.044156 & -4.727125 & 0.0000 \\
\hline DINTLIBOR & -1.409267 & 0.141139 & -9.984925 & 0.0000 \\
\hline GRPCPI & 5.774646 & 1.222388 & 4.724071 & 0.0000 \\
\hline GRPCPI^2 & -23.76622 & 4.367371 & -5.441769 & 0.0000 \\
\hline PRPCF
\end{tabular}

Prob(F-statistic) $\quad 0.000000$ 
Model 4 Full model: Growth, financial ratios and the cost of macroeconomic instability

Dependent Variable: GR?

Method: GLS (Cross Section Weights)

Date: 07/29/01 Time: 08:58

Included observations: 12

Number of cross-sections used: 134

Total panel (unbalanced) observations: 1415

Cross sections without valid observations dropped

\begin{tabular}{|l|c|c|c|c|}
\hline \multicolumn{1}{|c|}{ Variable } & Coefficient & Std. Error & t-Statistic & Prob. \\
\hline LA? & 0.041949 & 0.023158 & 1.811451 & 0.0703 \\
\hline PI? & 0.639467 & 0.279633 & 2.286807 & 0.0224 \\
\hline PH? & -0.282274 & 0.095160 & -2.966310 & 0.0031 \\
\hline TH? & 0.040833 & 0.027089 & 1.507374 & 0.1320 \\
\hline DE? & -0.016979 & 0.025980 & -0.653529 & 0.5135 \\
\hline GRPCPI*LA? & -0.220774 & 0.161948 & -1.363237 & 0.1731 \\
\hline GRPCPI*PI? & -1.942677 & 2.071316 & -0.937895 & 0.3485 \\
\hline GRPCPI*PH? & 3.231432 & 1.107204 & 2.918550 & 0.0036 \\
\hline GRPCPI*TH? & -0.039860 & 0.170423 & -0.233888 & 0.8151 \\
\hline GRPCPI*DE? & 0.091221 & 0.150220 & 0.607252 & 0.5438 \\
\hline GRRER & -0.165273 & 0.050076 & -3.300424 & 0.0010 \\
\hline RHO & -0.520020 & 0.159859 & -3.252987 & 0.0012 \\
\hline GRPCPI & 4.395913 & 1.322249 & 3.324573 & 0.0009 \\
\hline GRPCPI 2 & -19.02117 & 5.091128 & -3.736140 & 0.0002 \\
\hline PRP
\end{tabular}

Prob(F-statistic) 0.000000 


\section{REFERENCES}

1 BARRO, R. \& LEE, J.H. (1994) "Sources of economic growth", Carnegie-Rochester Conference Series on Public Policy (June): 1-46.

2 BARRO, R. (1997) The Determinants of Economic Growth, the MIT Press.

3 BRIAULT, C. (1995) "The cost of inflation", Bank of England Quarterly Bulletin 35 (February): 33-45.

4 CLARK, J.J., CLARK, M.T., \& OLSEN, G. (1990) "Sustainable growth and business combinations", in T.J. Kopp (ed.), Perspectives on Corporate Takeovers, Landam, NY: University Press of America.

5 CLARK, J.J., CLARK, M.T., \& VERZILLI, A.G. (1985) "Strategic planning and sustainable growth", Columbia Journal of World Business, Fall: 47-51.

6 CHURCHILL, N. \& MULLINS, J. (2001) "How FAST can your company afford to grow?", Harvard Business Review (May): 125-43.

7 DOYLE, B., BLAKLEY, D. \& MURRAY, L.W. (1994) "Threshold margins, growth and inflation", European Journal of Operational Research, 74: 257-72.

8 DONALDSON, G. (1985) "Financial goals and strategic consequences", Harvard Business Review, May-June: 57-66.

9 ELLSWORTHB, R.R. (1985) "Capital markets and competitive decline", Harvard Business Review, September-October: 171-83.

10 FRUHAN, W. (1986) "How fast should your company grow?", Harvard Business Review, (January-February): 84-93

11 GREENE, W.H. (2000) Econometric Analysis (4 ${ }^{\text {th }}$ ed.) New York: Prentice Hall.

12 HIGGINS, R. (1977) "How much growth can a firm afford", Financial Management, Fall: 7-16.

13 HIGGINS, R. (1981) "Sustainable growth under inflation", Financial Management, Autumn: 36-40.

14 HIGGINS, R. (1984) Analysis for Financial Management, Homewood, IL: Irwin.

15 HINKLE, L. \& MONTEIL, P. (1999) "Exchange rate misalignment: concepts and measurement for developing countries", Journal of Economic Literature, 38 (3): 651-59.

16 HOWE, K.M. (1988) "Valuation of the growth firm under inflation and differential personal taxes", Quarterly Journal of Business and Economics, Autumn.

17 JOHNSON, D. (1981) "The behavior of financial structure and sustainable growth in an inflationary environment", Financial Management, Autumn: 30-35. 
18 KOCKLERLAKOTA, N., (1996) "Implications of efficient risk sharing without commitment", The Review of Economic Studies, 63 (217): 595609.

19 LEWELLEN, W. \& KRALAN, W. (1987) "Inflation, corporate growth and corporate leverage", Financial Management, Winter: 29-36.

20 MURRAY, L.W., DOYLE, B. \& BLAKLEY, D. (1988) "A comprehensive planning model for incorporating goal tradeoffs", International Journal of Management, 5 (1): 88-97.

21 N'CHO-OGUIE, C., BLAKLEY, D., MURRAY, L.W. \& BEAUMONT SMITH, M. (2001)"Firm growth in inflationary environments", African Finance Journal, 3 (2): 28-49.

22 SEITZ, N. (1982) "Shareholder goals, firm goals, and firm financial decisions", Financial Management, Autumn: 20-26.

23 VAN HORNE, J.C. (1987) "Sustainable growth modeling", Journal of Corporate Finance, Winter: 19-25. 